\title{
Energy-Oriented Material Flow Simulation as a Contribution to Automotive I ndustry 4.0
}

\author{
Marco Seewaldt ${ }^{*}$, J oachim Nagel ${ }^{2 * *}$, Dieter Geckler ${ }^{3}$, Uwe Bracht ${ }^{4}$ \\ IInstitut für Maschinelle Anlagentechnik und Betriebsfestigkeit, Technische Universität Clausthal, \\ Leibnizstraße 32, 38678 Clausthal-Zellerfeld, Germany; *marco.seewaldt@imab.tu-clausthal.de \\ ${ }^{2}$ Volkswagen Aktiengesellschaft, AutoUni, Institut für Produktion, Logistik und Komponente, \\ Hermann-Münch-Straße 1, 38440 Wolfsburg, D Germany; **joachim.nagel@volkswagen.de \\ ${ }^{3}$ Volkswagen Aktiengesellschaft, Produktionsplanung Marke Volkswagen, Projekt Digitale Fabrik, \\ Berliner Ring 2, 38440 Wolfsburg, Germany \\ ${ }^{4}$ Institut für Maschinelle Anlagentechnik und Betriebsfestigkeit, Technische Universität Clausthal, \\ Leibnizstraße 32, 38678 Clausthal-Zellerfeld, Germany
}

SNE 27(2), 2017, 61 - 66, DOI: 10.11128/sne.27.tn.10371

Received: May 25, 2017,

Accepted: June 10, 2017 (Special Issue Review)

SNE - Simulation Notes Europe, ARGESIM Publisher Vienna ISSN Print 2305-9974, Online 2306-0271, www.sne-journal.org

\begin{abstract}
This article shows approaches to simulationbased improvements in energy and resource efficiency of automotive production processes. The concept of simulation oriented energy management enhances the quality of planning energy-efficient production systems. Moreover, it is an aim to reduce energy costs by improving the manufacturing management and control. The simulation software Plant Simulation (Siemens PLM) is used for the analysis of the potential energy savings. In the future, a connection with the real production control will become possible. Such selfoptimizing production systems build the core of the muchdiscussed term 'Industry 4.0'.
\end{abstract}

\section{I ntroduction}

For years, energy factors gained in importance for industrial production planning processes and the operation of facilities [1,2]. Volkswagen AG integrates the energy and resource consumption of production processes gradually as new parameters in the methods and software tools of the Digital Factory. A cooperation exists at the Technical University of Clausthal (TUC), Institute of Plant Engineering and Fatigue Analysis. One focus of the joint activities is the energy-oriented material flow simulation with the software tool Plant Simulation regarding the consumption of electrical energy and compressed air.

\section{Potentials of Energy-Oriented Material Flow Simulations}

The significant potential of energy-oriented material flow simulations results on the one hand from improvements of the production planning quality and on the other hand from the untapped opportunities of simulation-based energy management of production facilities. In the past the energy consumption of production processes has been statically estimated in the planning stage with a high level of inaccuracy without considering the dependencies on various energy sources. The usual safety margins often led to overdesigned infrastructure for electrical energy and compressed air, which is accompanied by extensive wastage.

In some brownfield factories, new technologies cause a lack of transparency of the energy consumption of the future production processes. This can lead to an insufficiently dimensioned energy production or use, which reduces the reliability of the new production facilities. This risk can be avoided by a simulation-based forecast of the consumption of all major forms of energy and resources.

Beyond a better prediction, new optimization potentials can be researched with valid energy-oriented simulation models. Differences in cycle times and system failures cause inefficient waiting times and offer many variation in the material flow, which can be identified by simulation. On this basis, energy efficiency measures can be implemented while remaining throughput neutrality. 


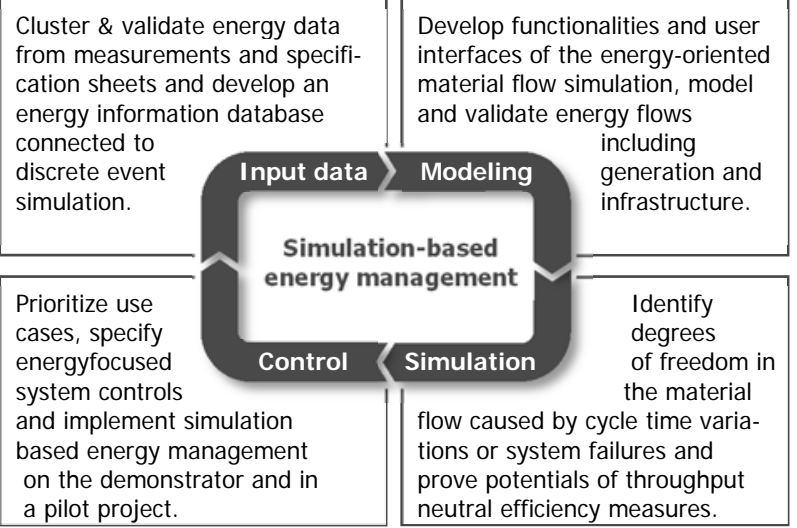

Figure 1: Fields of action of the simulation based energy management as closed loop system between physical and virtual production.

The influences of the material flow control actions on the energy consumption of production lines or entire factories can be analysed in detail. Then, decisions can be made and implemented accordingly. Systematic controls of buffer entry and storage exit strategies, which are essential for the production process, can be used foresighted into, identify periods in which power saving or standby modes are reasonable.

Results from these new measures and their evaluation promise great improvement potentials already in the planning phase of production facilities. In addition, Volkswagen pursues the vision 'Industry 4.0'. This strategy promotes the development of real time capable and intelligent networking of people, objects and systems taking advantage of all possibilities provided by current information technologies [3]. In view of the increased networking capability of production plants and the usage of sensor technologies horizontal on the shop floor and vertical in PC-based planning systems. New application areas of established software tools in the Digital Factory are conceivable [4]. Today, simulation studies in the automotive production are focussed on the factory planning process. In the future they might also provide reasonable assistance to optimize the ongoing production (Figure 1).

The efficiency potential of connected facilities by simulation-based energy-efficient and peak load controlled systems is currently not used, although appropriate communication protocols between shop floor and ERP levels have existed for years. A major barrier is the poor availability of essential simulation input data, which often still has to be measured by hand. Due to sensor technologies and connected devices this should cause no difficulties in the future.

\section{Analysis of Potential Savings in the Production Areas of the Automotive I ndustry}

The energy consumption of the automobile production causes about $20 \%$ of $\mathrm{CO}_{2}$ emissions throughout the life cycle of a Golf VII. Volkswagen emits about $25 \%$ inhouse while the rest falls to its suppliers. The supplier's share is $75 \%$ because of their extremely energy intensive processes such as the production of steel, aluminium, plastics, paints, tires and windows.

The internal portion of Volkswagen is equally divided between the component manufacturing and the vehicle manufacturing. In the component manufacturing the business areas of foundry, gear drive and engine have very high energy consumptions. In the vehicle manufacturing it is the paint shop which has the highest needs. These main production areas thus offer high potentials for an energy-oriented material flow simulation (Figure 2).

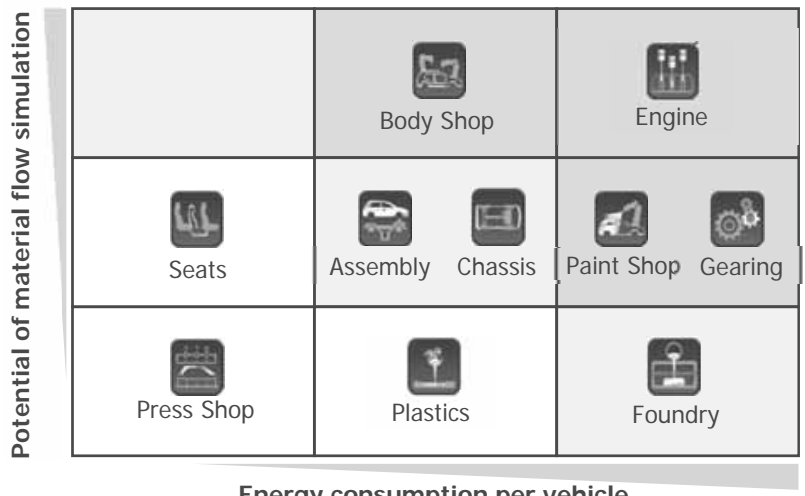

Figure 2: Potential analysis of the energy-oriented material flow simulation in the main production areas of Volkswagen AG.

However, from the perspective of the material flow they promise a different potential. The in-house material flow of a foundry has little impact on its energy consumption, while sufficient degrees of freedom for optimization can be observed in the production lines of the business fields of engine and gearing as well as in the paint shop.

Therefore, due to the complexity of the material flow in the body shop, this main production unit promises a high worthiness for simulation analysis, although the power consumption is relatively low in comparison to the complete production process of a vehicle. 
Rather uninteresting for an energy-oriented material flow simulation is the press shop, which operates impressive large press lines, but their high energy consumption is compensated by an even higher productivity.

\subsection{Holistic modelling of several energy sources and infrastructure levels}

Before the simulative evaluation of concrete use cases it was necessary to develop further energy-oriented functionalities for the software tool Plant Simulation to model the energy flows including their generation and infrastructure. The most cost intensive energy sources in the automobile production are electrical energy and compressed air, thus corresponding use cases were selected. A distinction must be made between the infrastructure levels of the involved production facilities.

Following the successful implementation of the required functions on the level of a production line for crankshafts, the interaction between an air compressor and the high-pressure air cleaners which it supplies can be analyzed (Figure 3). The level of detail for modeling the power consumption of the compressor in relation to its internal control is as detailed as the compressed air consumers and the inducing material flow of the crankshafts. This allows an accurate dimensioning and selection of the compressors as well as a fine tuning of the internal compressor controller.

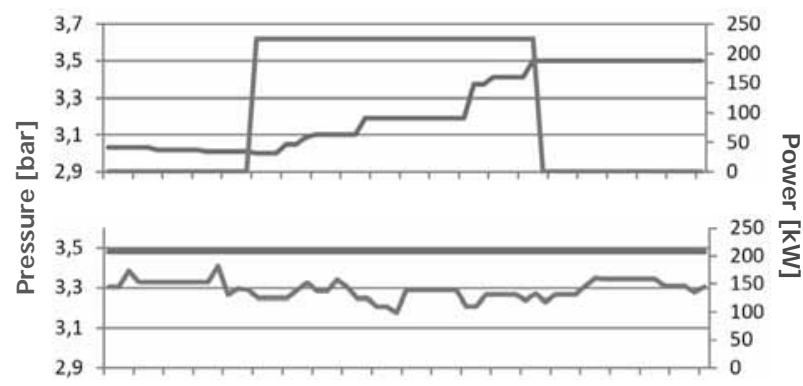

Figure 3: Pressure pattern and electrical power consumption of an air compressor plant with intermitted control (top) and continuous control (bottom).

At the level of an engine plant different control modes of an air compressor plant network can be examined by the same simulation objects. Moreover, typical problems of material flow studies can be skilfully linked with production analyses on energy-efficiency. While comparing the energy and resource consumption of a push production strategy with an alternate demand control strategy, the key figures of productivity as well as energy and resource consumptions can be reliably predicted.

\subsection{Simulation based utilization of degrees of freedom in material flows}

Based on the developed functionalities, degrees of freedom in the material flow can be identified and efficiency measures can be ensured. The output has to be secured because the productivity of a large-scale production is inviolable. But even in highly utilized production lines, both in component and in vehicle manufacturing, energy savings of about $3 \%$ could be identified. Their implementation is not economical for existing production lines since the necessary control technology would have to be retrofitted.

As part of the redesign of production processes, these savings can be achieved without generating extra costs. The potential might be even higher when thinking of future fully automated small series production lines with a smaller degree of capacity utilization.

These potentials are generally based on degrees of freedom in the material flow of interlinked production lines whose plants generate unproductive waiting times, for example by different cycle times or system failures. Two types of effective control systems can be distinguished: The power saving control (Figure 4) and the peak load control (Figure 5).

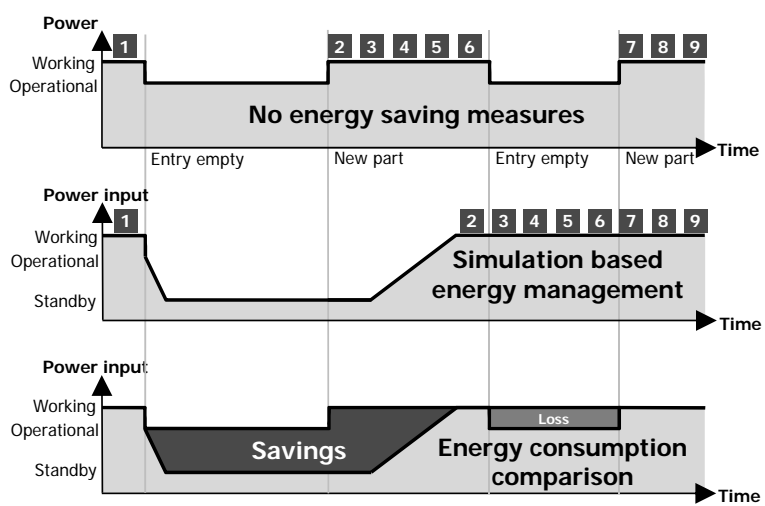

Figure 4: Potential of a power saving control system using the example of the electrical power input of a transfer line with standby-mode.

An energy saving controller tries to keep the standby breaks of a production as long as possible, without thereby generating a loss of throughput. So it is clear that such a control must not be applied to the bottleneck facility in a linked production line. After effectively shutting down, production lines typically require a startup time, so more than one sensor at the entry and exit is needed to control the machines: The system must be able to foresee future waiting times to generate maximum energy savings [5] (Figure 4). 


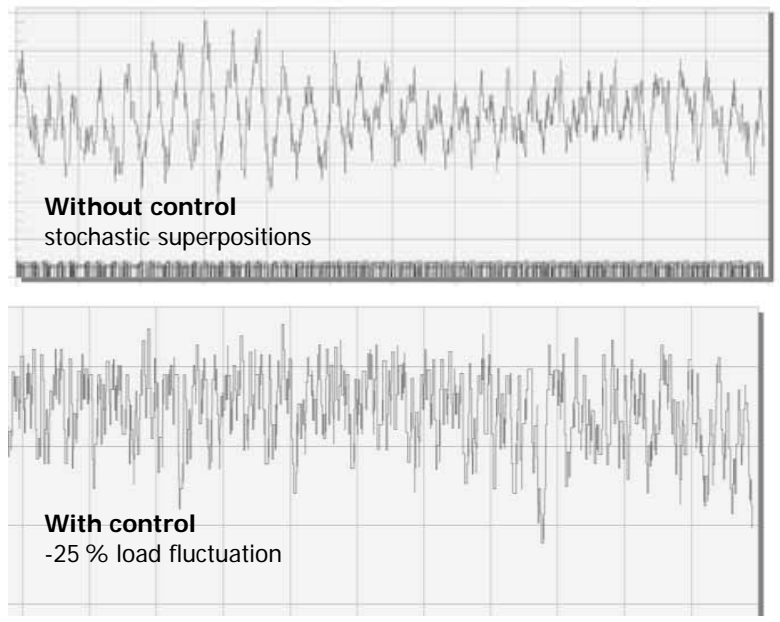

Figure 5: Savings of a peak load control using the example of the pressure profile of a crankshaft production with 20 high-pressure air cleaners.

While the power saving control causes a direct saving of electrical energy by the extension of standby breaks, the peak load control primarily aims at the process safety of a compressed air system. The target figure is not the consumption of compressed air but the load fluctuation in the compressed air network. Systems powered by compressed air often have a shorter cycle time than their corresponding production line, therefore simultaneity in the usage of compressed air can be avoided by specific delays without creating output quantity losses. Due to the secure avoiding of unfavourable stochastic superpositions of several machines, an otherwise necessary oversizing of the air compressors can be omitted. Once again savings in electrical energy consumption of air compressors can be achieved and operated in a more constant way (Figure 5).

\section{Designing Decoupling Buffers in the Car Body Shop Con- sidering Energetic Aspects}

Interlinked manufacturing systems are decoupled by buffers to maintain the production. Continuous cycle time fluctuations are a crucial problem in the planning of particular clocked production plants when determining the optimal buffer size. These fluctuations and the failure of any single process can lead to the failure of the entire production system. The disturbances and failures cause a reduction of the overall system performance. The use of buffers to decouple the processes can reduce these impairments and improve the system output.
However, expenses arise for the space and the necessary technical equipment. In particular, decoupling buffers serve two main purposes: They reduce the idle time of the subsequent process by taking parts out of the buffer. Even in the case of a breakdown of the preceding section the production can be sustained. Conversely, parts can still be moved into the buffer if the succeeding production area is disturbed.

This also applies to the car body shop in the automotive industry. An entire vehicle body consists of several modules which are produced parallel to each other and assembled in the correct order (Figure 6).

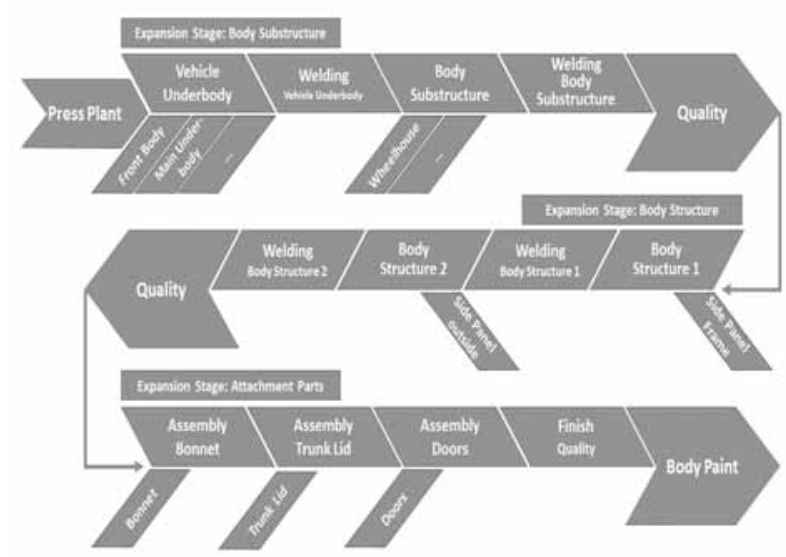

Figure 6: Sequence of a car body production [6].

The production line of one module typically consists of three to five individual production cells which are linked by defined transfer points. In current production lines of the automotive industry not every production cell is decoupled by a buffer but on average every second production unit. These buffers are quite small and can contain four to eight parts. At the end of a module production area as well as between the process steps of the main production line much larger buffers are installed with a size of up to one hundred storage units.

\subsection{Building the energy-oriented material flow simulation model}

With the computer-aided tools and methods of the Digital Factory, in particular the material flow simulation, the output of a production plant is proved and thus also the quantity and the size of the buffers contained can be set [7]. However, for dimensioning the decoupling buffers so far only the target figures mentioned above were considered. A setup under energetic aspects, which makes more energy-efficient production processes possible, did not take place. 


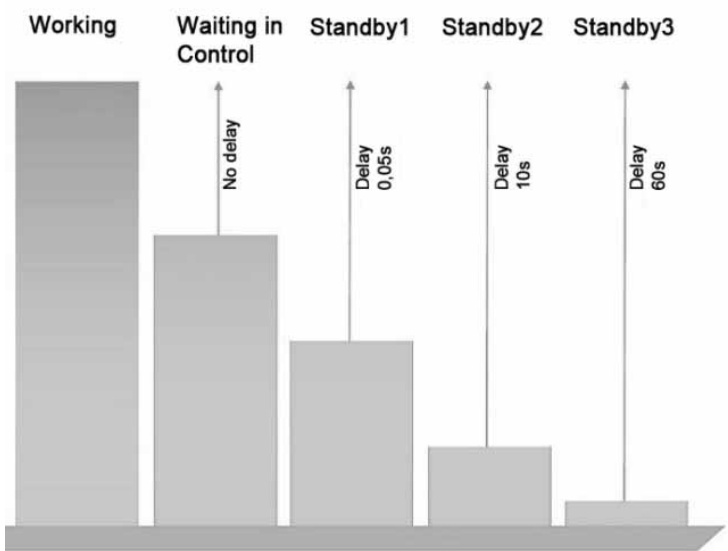

Figure 7: Energy states of an industrial robot [8].

Robots and machines in the body shop can operate more energy-efficient than it is usual today. An analysis of a current manufacturing facility showed that robots have an average of $30 \%$ to $60 \%$ idle times. Thus, a switch to standby or powering down at the right time can save electrical energy. Modern robots even have different standby modes which are associated with corresponding different time lengths to power up again (Figure ).

Schacht [6], Brüggemann [9] and Meike [10] have proven that robots can save energy by decreasing the acceleration and the speed of movement for the same trajectory, but possibly at the expense of a longer cycle. The intensity of the acceleration has a significant impact on the total energy consumption [6,9]. In conjunction with the reduction of speed, a local minimum of energy consumption can be observed $[6,9,10]$. Further energyefficiency measures can be achieved by positioning the operating point (height, distance, home position) as well as the optimization of the trajectory in a "more natural and smoother" way [9].

As studies of Volkswagen AG and TUC have shown such material flow simulations are able to provide reliable energy consumption forecasts of production processes. In a second stage the usage of smart behaviour during bottlenecks due to system breakdowns will be analysed. The system can be switched to a slower but more energy-efficient operating mode and to standby. The subsidiary process and the subsequent process of the main production line were analysed with energyoriented material flow simulations.

An initial check of each robot and machine has to clarify if it is allowed to be switched to power saving operating modes. For example, this is not allowed for trajectory-welding which must be carried out with a defined speed to meet the quality targets.
Also gluing stations may not be shut down because the glue would harden inside the station. By contrast, handling tasks or point-welding operations can be operated in several power saving modes.

These energy-oriented control options, standby and a slower but more energy-efficient operating mode, have to be implemented in an intelligent way under the premise of throughput neutrality. The following approaches have been entered into the control system:

- A cell is switched to standby if the upstream buffer is empty and it is waiting for a new part.

- If the following buffer is full and the subsequent production cell is disturbed, blocked or in standby mode, the current cell is switched to standby.

- The cell will begin to work in slow energy-efficient operating mode if the succeeding buffer reached a specific occupancy rate. It will work again at full speed, if a lower specific occupancy rate is reached.

For example, a cell with a subsequent buffer with the size of 6 parts switches the slow energy-efficient operating mode on if the buffer has stored 4 parts. It will resume work in full speed, only if 2 remaining parts are stored in the buffer. On the other hand, if the buffer works his way up to full occupancy the cell switches into standby and will be turned on again, accordingly again in the slower mode, if 2 parts are taken out by the following cell.

\subsection{Results of the energy-oriented simulation studies}

In the simulation studies the number of buffers, the buffer sizes and the limits for activating and deactivating the power saving modes vary. Simulation experiments without any intelligent energy state behaviour are used as reference for comparison. The maximum size of the decoupling buffers within the subassembly group is limited by the movement of the robots so that every storage place is within operating distance.

A reduction of the buffer sizes can be neglected since the buffers have already been dimensioned to achieve the intended throughput. Based on the research results of Schacht [6], Brüggeman [9] and Meike [10] the slower operating mode was set to $85 \%$ energy consumption with a cycle time increased by $15 \% .12$ observations per experiment were performed within 50 days plus 10 days to initialize the simulation runs. 


\begin{tabular}{llll}
\hline Experiment & $\begin{array}{l}\text { Throughput } \\
\text { [units/50days] }\end{array}$ & $\begin{array}{l}\text { Consumption } \\
{[\mathrm{kWh}]}\end{array}$ & $\begin{array}{l}\text { Consumption } \\
\text { per part [kWh] }\end{array}$ \\
\hline Reference & $57.459,83$ & $279.197,91$ & 4,859 \\
\hline $\mathbf{4 * / 4 * * / 2 * * *}$ & $57.015,50$ & $260.043,92$ & 4,561 \\
\hline $\mathbf{4 / 4 / 1}$ & $57.183,67$ & $253.529,24$ & 4,433 \\
\hline $\mathbf{5 / 5 / 3}$ & $57.577,42$ & $260.241,04$ & 4,521 \\
\hline $\mathbf{5 / 5 / 2}$ & $57.543,42$ & $253.622,14$ & 4,407 \\
\hline $\mathbf{5 / 5 / 1}$ & $57.603,25$ & $253.136,54$ & 4,394 \\
\hline $\mathbf{5 / 4 / 2}$ & $57.562,00$ & $250.479,10$ & 4,351 \\
\hline $\mathbf{5 / 4 / 1}$ & $57.633,25$ & $249.838,91$ & 4,335 \\
\hline $\mathbf{5 / 3 / 1}$ & $57.638,58$ & $249.061,58$ & 4,321 \\
\hline
\end{tabular}

Table 1: Simulation of a part of the body shop with energy-efficient strategies.

* Buffer Size, $* *$ Slow on $>=\mathrm{x}, * * *$ Normal mode on $<=\mathrm{x}$

Overall more than 50 studies with different combinations of buffer sizes and upper and lower limits for the power saving modes were performed. Table 1 shows an extract of these results.

The first line shows the reference values without any changes of the buffers or benefits of energy-efficient controls. If the energy efficiency measures are switched on, an unchanged buffer size cannot achieve the same output. Nevertheless, in principle the energy efficient measures are working. For a decrease of $0.5 \%$ output the energy consumption could be reduced by $8.8 \%$. However, with the increase of the buffer by only one unit, the energy consumption could be reduced up to $11 \%$ with at least the same quantity of parts produced. It can be assumed that energy-efficient controls are more effective the longer they last.

\section{Summary and Outlook}

By the integration of existing approaches of material flow simulations with energy consumption aspects, the energy-oriented material flow simulation makes a new contribution to the ongoing development of the tools and methods of the Digital Factory. This can extend future planning processes of production facilities with the ability to dimension the technical building equipment more precisely. Through the application of power saving controls the energy consumption of production processes can be reduced while maintaining throughput neutrality. However, further research is needed to determine if the greater effort in planning and operating is cost-effective.
The prevailing pressure on productivity and costs in the automotive industry makes it difficult to test and implement innovative approaches towards a smart and more energy- and resource-efficient factory. However, given the ever increasing number of variants, customizing of individual products and further increasing energy prices, future applications are predictable.

The material flow simulation is currently almost exclusively used in the planning process. New problems arising during the operation of the plant are not analysed with existing simulation models, but are solved manually with best practice knowledge. The goal must be to utilize the simulation know-how in the current production and expand the collaboration between planning and operation of a plant. This can also help to raise awareness of the employees for a more energy-efficient production.

\section{References}

[1] Hopf, H. Methodik zur Fabriksystemmodellierung im Kontext von Energie- und Ressourceneffizienz. Wiesbaden: Springer Vieweg Verlag; 2016. 218 p.

[2] VDI Technical Division Production and Logistics. Studie Produktion und Logistik in Deutschland 2025 - Trends, Tendenzen, Schlussfolgerungen. Düsseldorf: VDI Verlag; 2012. 32 p.

[3] Volkswagen Aktiengesellschaft. Geschäftsbericht. Wolfsburg; 2016. 422 p.

[4] Bauernhansl T, ten Hompel M,Vogel-Heuser B. Industrie 4.0 in Produktion, Automatisierung und Logistik. Wiesbaden: Springer Vieweg Verlag; 2014. 648 p.

[5] Wolff D, Kulus D, Nagel J. Simulationsgestützte Bewertung von Energiesparstrategien. 2013; ZWF Jahrgang 108 (03/2013): 103-108.

[6] Schacht, M. Erweiterung des Planungsprozesses im Karosserierohbau um Energieaspekte zur Auslegung der Technischen Gebäudeausrüstung [dissertation]. [Institut für Konstruktions- und Fertigungstechnik]. Universität der Bundeswehr Hamburg; Aachen: Shaker Verlag; 2014. 144 p.

[7] Bracht U, Geckler D, Wenzel S. Digitale Fabrik. Berlin: Springer Verlag; 2011. 419 p.

[8] KUKA Aktiengesellschaft. Energieeffiziente Produktion mit KUKA Robotern am Beispiel des Karosseriebaus. Augsburg; 2011. 35 p.

[9] Brüggemann H, Laumeyer M, Kroh R. Effiziente Programmierung senkt den Energieverbrauch von Robotern. 2013; MM MaschinenMarkt 50/2013: 90-93.

[10] Meike, D. Increasing Energy Efficiency of Robotized Production Systems in Automobile Manufacturing [dissertation]. [Faculty of Industrial Electronics and Electrical Engineering], Riga Technical University; Riga: RTU Press; 2013. 214 p. 